\title{
Minimally invasive sutureless aortic valve replacement in the Redo setting: the new surgical frontier in the valve-in-valve era
}

\author{
Giuseppe Santarpino $^{1,2,3}$, Ferdinand $\operatorname{Vogt}^{1}{ }^{1}$ Pasquale Mastroroberto ${ }^{3}$ \\ ${ }^{1}$ Department of Cardiac Surgery, Paracelsus Medical University, Nuremberg, Germany; ${ }^{2}$ Department of Cardiac Surgery, Citta di Lecce Hospital, GVM \\ Care \& Research, Lecce, Italy; ${ }^{3}$ Cardiac Surgery Unit, Department of Experimental and Clinical Medicine, Magna Graecia University, Catanzaro, Italy \\ Correspondence to: Dr. Giuseppe Santarpino. Department of Cardiac Surgery, Città di Lecce Hospital - GVM Care \& Research, Lecce, Italy. \\ Email: g.santarpino@libero.it.
}

Submitted Sep 05, 2019. Accepted for publication Oct 30, 2019.

doi: $10.21037 /$ acs.2019.11.03

View this article at: http://dx.doi.org/10.21037/acs.2019.11.03

The horizon of a future without aortic valve surgery, in which only interventional approaches will be used, raises the question of how should those patients be treated for whom transcatheter aortic valve implantation (TAVI)/ valve-in-valve $(\mathrm{Vin} V)$ procedure is contraindicated. For these patients, there will also be increasing demand for optimal results at the price of minimal surgical risk. Patients with contraindication for TAVI (either for technical or anatomical reasons) are among those notably at highest risk. Therefore, for this patient population, the new frontier could be a minimally invasive approach with the use of sutureless/rapid-deployment prostheses, which allows shorter ischemic times, thus contributing to reduce surgical risk within an "integrated" risk reduction strategy.

Due to the increased life expectancy of the aging population and widespread use of bioprostheses over the past years (1), many patients still require surgical aortic valve replacement (AVR) or re-replacement (re-AVR). Despite the higher risk, especially in the setting of infective endocarditis, these procedures have shown encouraging results (1). Notwithstanding this, redo surgery for AVR is considered as a 'too' high-risk procedure, given that TAVI or VinV-TAVI may potentially be offered to all patients.

For these reasons, in patients undergoing reintervention (re-AVR or redo cardiac surgery) for isolated AVR, previous experience has suggested minimally invasive surgical approaches using J-shaped ministernotomy (2-4). Only limited data is available on the feasibility of minimally invasive approaches in redo patients. Recently, the Sutureless and Rapid-Deployment Aortic Replacement Valve International Registry (SURD-IR) has collected data on 63 patients undergoing reintervention through a minimally invasive approach using a sutureless prosthesis. In this series, neither conversion to full sternotomy nor inhospital deaths occurred.

Obviously, the decision to treat via surgical reintervention or minimally invasive reintervention and not using the TAVI/VinV procedure should be tailored to the individual patient. The adoption of minimally invasive AVR techniques remains questionable for patients with a patent left internal mammary artery, requiring isolation and clamping to provide myocardial protection (2-4). In the process of decision-making, minimally invasive techniques allow for less extensive mediastinal dissection and minimize surgical trauma, thus reducing the risk of operative bleeding, procedure-related complications and graft injury associated with sternal re-entry (2-4).

Moreover, reoperation may be required as not all redo patients can undergo a safe TAVI or VinV intervention (e.g., too-small implanted bioprosthesis, low coronary takeoff). Conversely, all these conditions can be safely managed during open surgery. Patients amenable to this treatment strategy are not few in terms of prevalence, given the increasing adoption of biological valves in younger patients as well as the unfavorable results of some biological models widely implanted in recent years $(5,6)$.

Our considerations are notably largely speculative, given that evidence on the use of sutureless prostheses in redo procedures derives mostly from single-center experiences with small sample size (7). In particular, only one study compared sutureless vs. VinV implantation, in which both procedures were found to be effective and 
safe in preventing the occurrence of paravalvular leakage but with a better capacity of sutureless prostheses to minimize patient-prosthesis mismatch (7). Despite the presence of patient-prosthesis mismatch, no differences in clinical outcome and quality of life were observed at follow-up. In addition, transcatheter VinV implantation has been proposed as a viable option in 'all' redo patients, despite being burdened by significant limitations (e.g., some prosthetic models with biological leaflets mounted outside the stent) (8). The VinV procedure also results in significant patient-prosthesis mismatch, occurring in almost $50 \%$ of patients (9). Data on redo procedures using a minimally invasive approach have shown shorter operation times and lower risk for sternal instability or infection. All these elements contribute to lower intraoperative morbidity and mortality (2).

Therefore, in this perspective, we hypothesize that in the redo setting, the use of sutureless/rapid-deployment prostheses, though currently contraindicated, could represent a new frontier if we consider that most patients are affected by endocarditis. In fact, the use of prostheses in cases of endocarditis is currently off-label and still under investigation.

Although we do not see any limitations to this technique, in young and older patients alike, the surgeon's experience with the non-redo minimally invasive approach and use of sutureless prostheses is crucial before performing minimally invasive redo procedures.

Previous experience and speculation about the future of cardiac surgery-for example when coronary stents were introduced-teach us that expectations from the cardiology world are not always met but, on a positive note, have led to 'integrated' treatment strategies with indications for patienttailored procedures; in other words, they have led to the creation of the heart team. One thing the heart team should know is that there are, and will be, many patients who require surgical reintervention for aortic valve/prosthesis replacement. Our experience to date leads us to believe that, for these carefully selected patients, the addition of the 'weapons' consisting of (I) a minimally invasive approach and (II) the use of sutureless prostheses can contribute to improve outcomes. Therefore, both should be questioned within the heart team discussions in order to choose the best treatment option for the patient.

\section{Acknowledgments}

None.

\section{Footnote}

Conflicts of Interest: The authors have no conflicts of interest to declare.

Open Access Statement: This is an Open Access article distributed in accordance with the Creative Commons Attribution-NonCommercial-NoDerivs 4.0 International License (CC BY-NC-ND 4.0), which permits the noncommercial replication and distribution of the article with the strict proviso that no changes or edits are made and the original work is properly cited (including links to both the formal publication through the relevant DOI and the license). See: https://creativecommons.org/licenses/by-nc-nd/4.0/.

\section{References}

1. Onorati F, Biancari F, De Feo M, et al. Mid-term results of aortic valve surgery in redo scenarios in the current practice: results from the multicentre European RECORD (REdo Cardiac Operation Research Database) initiative. Eur J Cardiothorac Surg 2015;47:269-80.

2. Mikus E, Calvi S, Tripodi A, et al. Minimally invasive reoperative aortic valve replacement. Ann Cardiothorac Surg 2015;4:67-70.

3. Gillinov AM, Casselman FP, Lytle BW, et al. Injury to a patent left internal thoracic artery graft at coronary reoperation. Ann Thorac Surg 1999;67:382-6.

4. Gaeta R, Lentini S, Raffa G, et al. Aortic valve replacement by ministernotomy in redo patients with previous left internal mammary artery patent grafts. Ann Thorac Cardiovasc Surg 2010;16:181-6.

5. Silaschi M, Conradi L, Treede H, et al. Trends in surgical aortic valve replacement in more than 3,000 consecutive cases in the era of transcatheter aortic valve implantations. Thorac Cardiovasc Surg 2016;64:382-9.

6. Sénage T, Le Torneau T, Foucher Y, et al. Early structural valve deterioration of Mitroflow aortic bioprostheses. Circulation 2014;130:2012-20.

7. Santarpino G, Pietsch LE, Jessl J, et al. Transcatheter aortic valve-in-valve implantation and sutureless aortic 
valve replacement: two strategies for one goal in redo patients. Minerva Cardioangiol 2016;64:581-5.

8. Chiariello GA, Villa E, Messina A, et al. Sutureless prosthesis for failed small Mitroflow valves: the Percevalafter-Mitroflow procedure. Interact Cardiovasc Thorac

Cite this article as: Santarpino G, Vogt F, Mastroroberto P. Minimally invasive sutureless aortic valve replacement in the Redo setting: the new surgical frontier in the valve-in-valve era. Ann Cardiothorac Surg 2020;9(4):325-327. doi: 10.21037/ acs.2019.11.03
Surg 2018;26:865-8.

9. Santarpino G, Pfeiffer S, Fischlein T. Sutureless aortic valve replacement to prevent patient-prosthesis mismatch in the era of valve-in-valve implantation. J Thorac Cardiovasc Surg 2012;144:279-80. 